fracture of the earth's crust which runs in a south-westerly direction from Inverness.

9. That all the observers who heard the noise agree in stating that it was a "rumbling" sound.

I0. That of the fourteen observers within 38 miles of the source who felt the shock, thirteen of them mention having heard the rumbling noise, and none of the other olservers in Scotland mention noise as an accompaniment of the earthquake, and hence that the noise was confined chiefly, if not entirely, to places situated near the source.

II. That the stations where the noise was heard were for the most part situated on hard dense rocks, with little or no soil near them.

12. That the average duation of the disturbance was $4^{\circ} 4$ seconds for observers situated within the sound area.

13. That of twenty-two lighthouse observers between Cape Wratb and the Mull of Galloway who were situated on the older formations (Laurentian, Cambrian, and metamorphosed Lower Silurian) eleven felt the shock, whilst of thirteen observers situated on newer rocks it made itself known only to two of them, and that the earthquake was therefore more generally felt on the older rocks of Scotland.

14. That stations situated near one another and on the same formation did not necessarily both receive the shick, and that faults and trap dykes did not seem to affect the passage or intensity of the wave in any way.

15. That the observations of time at Armagh, Belfast, and Omagh show that the shocks at these places were most probably propagated direct from Phladda in Scotland, and that the severity of the shock and the "rumbling" noises heard in and around Leterkewny were probably due to a second and local source of disturbance generated by the arrival of the shock from Phladda.

\section{MAGNETIC DECLINATION}

r. $[\mathrm{T}$ is well known that Prof. Rudolph Wolf has endeavoured to render observations of sun spots made at different times, and by different observers, comparable with each other, and has thus formed a list exhibiting approximately the relative sun-spot activity for each year. This list extends back into the seven teeth century, and is unquestionably of much value. Nevertheless it must be borne in mind that we possess no sun-spot data sufficiently accurate for a discussion in a complete manner of questions relating to solar periodicity before the time when Schwabe had finally matured his system of solar observations, which was not until the year 1832 .

We have however a much longer series of the diurnal ranges of magnetic declination. Now these are already well known to follow very closely all the variations of sun-spot frequency, being greatest when there are most, and least when there are fewest spots; and it may even be imagined that sach ranges give us a better estimate of true solar activity than that which can be derived from the direct measurement of spotted areas.

The long-period inequalities of the diurnal range of magnetic declination are thus, we mav imagine, precisely those of solar activity, so that to analyse the former is probably equivalent to analysing the latter.

2. Our method of analysiz is not new. The system pursued by us is in fact that which has been pursued by Baxendell, and

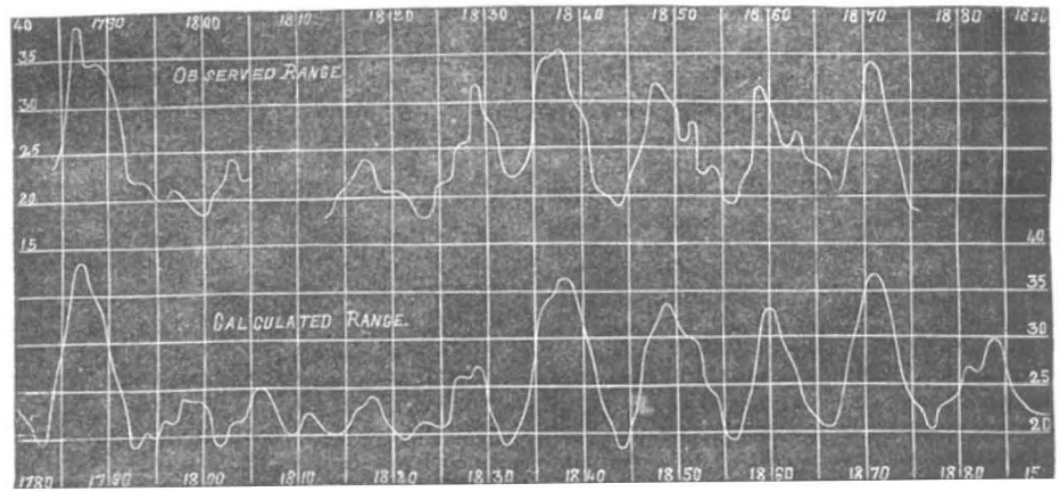

probably other astronomers, with observations of variable stars, and it has already been applied by one of us in a preliminary manner to magnetic declination ranges (Proc. Lit. and Phil. Society, Manchester, February 24, 1880 ).

3. The observations at our disposal are those which have been used by Prof. Elias Loomis in his comparison of the mean daily range of the magnetic declination with the extent of the black spots on the surface of the sun (American Fournal of Science and $A r / s$, vol. 1., No. cxlix.). These observations are recorded as monthly means of diurnal declination range, and we found it necessary to multiply each by a certain factor, firstly, on account of the well-known annual inequality of declination range, and secondly, to bring them all to the standard of the Prague observations. We have applied for this latter purpose precisely the same corrections as those made by Prof. Loomis

4. The result of an analysis of these observations has been to indicate the exis tence of three inequalities : two dominant ones with feriods of about ro $\frac{1}{2}$ and 12 years, and a subsidiary one with a period of about $16 \frac{1}{4}$ years. By these means we have beeen enabled to reproduce the observed annual values of declination range with an average difference of $39^{\prime \prime}$. The amount of agreement between the observed and calculated values will be seen from a diagram which accompanies this note. We are however of opinion that the series of observed values at present obtainable is too short to render this analysis a very accurate one. It will certainly not bear carrying back forty or fifty years beyond its starting-point, which was in 1784 , and it would be very hazardous to carry it forward any considerable length into the future. We may however mention that our calculations indicate a maximum of declination range about $\mathbf{1 8 8 4}$, but not so pronounced a maximum as that of $187 \mathrm{I}$.

5. During our analysis an observation was mate by us which we think worthy of record.

It is a well-known fact that the so-called eleven-yearly oscillations of declination range are at certain times large, and at other times small. Thus, for instance, they have been large for the last forty years, but they were small about the earlier part of the present century. It is clear to us from an inspection of the observations that a series of large oscillations is accompanied with an exaltation of the base line, or line denoting average efficiency, while a series of small oscillations is accompanied with a depression of the same. The result is a long period curve of the base line, the beat period, so to speak, of the eleven yearly inequality.

Now a phenomenon precisely similar occurs in connection with shorter periods. If we take irequalities having a period of three or four months we find that such are alternately well developed or of large range, and badly developed, or of small range ; and that a large range of such is accompanied with an exaltation of the base line or line of average efficiency, while a small range is accompanied with a depression of the same. The result is a curve of the base line, of which the period is, roughly speaking, eleven years. May we not therefore imagine that the so-called eleven-yearly period, or, to speak more correctly, the

I " Yote on an Attempt to Analyse the Recorded Diurnal Ranges of Magnetic Declinatirn." By Balfour Stewart, M.A., LL.D., F.R.S., Professor of Natural Philosophy at the Owens College, and William Dodgson. Read at the Manchester Literary and Philosophical Society, March 8. 
ten and a half and twelve-yearly periods into which the eleven. yearly period may perhaps be analysed, may be in reality beat periods for shorter disturbances? Is it not therefor $\approx p$ ssible that a study of these shorter periods may give us information regarding the nature of the eleven-yearly period, whether for sun-spots or declination ranges, which the small series of actual observations is incompetent to afford?

We beg to take this opportunity of thanking $\mathrm{Mr}$. William Stroud for the help he has given us in this investigation.

\section{UNIVERSITY AND EDUCATIONAL \\ INTELLIGENCE}

CAMBridge.-At Trinity College the following distinguished graduates of the College bave been elected Honorary Fellows :Lord Rayleigh, M.A., F.R.S., Professor of Experimental Physics; Mr. Henry Sidgwick, M.A., Prælector in Moral and Political Philosophy, the author of "The Method of Ethics"; Mr. Edward Herbert Bunbury, M.A., author of "A History of Ancient Geography," \&c. ; and Mr. William Henry Waddington, B.A., Member of the French Institute, Jate President of the Council, and Minister of Foreign Affairs in France.

The Adams Prize is to be given in 1883 for a general investigation of the action upon each other of two closed vortices in a perfect incompressible fluid. In particular it is suggested that the case of two linked vortices should be fully discus ;ed, with the view of determining (I) whether any steady motion is possible, and (2) whether any motion can occur in which there are periodical changes in the forms and dimensions of the vortices. Each essay should be accompanied by a full and careful abstract pointing out the parts which the author considers to be new, and indicating the parts which are to be regarded as of more importance than the rest. The competition is open to all graduates of Cambridge; essays must be sent in on or before December $x 6,1882$. Essays must not be written in the candidate's own hand. The successful candidate will receive about $\mathrm{i} 7 \mathrm{ol}$. He must print the essay at his own expense. The examiners are the Vice-Chancellor, and Messrs, A. Freeman, W. H. Besant, and E. J. Routh.

VICTORIA UNIVERSITY. - The following summary of draft regulations on degrees, examinations, and courses of study has been issued :- -1 . These regulations are, with the exception of certain general proposals with reference to University Matriculation, confined to the subjects of Degrees, Examinations, and Courses of Study in the Faculties of Arts and Science. 2. According to the proposals in the Report any certified student of a College incorporated in the University may matriculate at certain times in the year, the definition of College studentship being left to the College or Colleges, subject in each case to the approval of the University. No University examinations leading to a degree will be open to any persons who are not matriculated students. 3. According to the proposals in the Report there are to be two distinct Faculties of Arts and of Science. The degrees in these faculties are to be those of B.A. and M.A. B.Sc. and M.Sc., and a Doctorate common to the two Faculties and varyirg as a Doctorate of Literature, of Philosophy, and of Science. 4. In consonance with a main principle of the University Charter, the degrees of B.A. or of B.Sc. are to be conferred upon students who bave passed certain prescribed University examinations, and who have attended certain prescribed University courses of study in a College of the University. 5. In the examinations for the degrees of B.A. and B.Sc., and in the privileges conferred by these degrees, a distinction is to be drawn between the Ordinary B.A. or B.Sc. degree, and the B.A. or B.Sc. degree with Honours. 6. The regular period of study required of candidates for the degrees of B.A. and B.Sc. is to be three years, of which two shall be after the date of their passing the Preliminary Examination (see $\S 7$ of this summary); but students who have passed the Preliminary Examination (see $\$ 7$ of this summary) next in date after their matriculation, and have been placed in the first division of the list of successful candidates, shall be allowed to proceed to their degree in two years. 7. All candidates for the degrees of B.A. or B.Sc. are required to pass a general examination called the Preliminary Examination, and to present themselves for this examination not later than two years from the date of their matriculation. Regular first year courses of study are arranged as preparatory for this Examination, to be taken by all students except those who pass it immediately after matriculation (see $\$ 6$ above), or who go through the first year's course of one of the Honours
Schrols approved by the University. 8. The subjects of the Preliminary Examination are arranged in two groups (A and $B$ ), in one of which every candidate must pasi. The essential difference between the two groups is that in A, Latin and Greek are compulsory, but that a choice is given between four subjects, including two modern languages and two elementary sciences; while in $\mathrm{B}$ a choice is given between the alternatives of two languages (ancient or modern) and one elementary science, or two sciences and one language (ancient or modern). In B the requirements in modern languages and mathematics are rather greater than in A. 9. The other examinations for the degrees of B.A. and B.Sc. will be open to such students only as have passed the Preliminary Examination, and as have attended the prescribed University courses of study in a College of the University. These further examinations will differ for students intending to present themselves for an Ordinary B.A. degree and for those desirous of a B.A. degree with Honours. 10. The desree of B.A. with Honours is to imply that a student has attended, during three years, prescribed courses of study (approved by the University) in a distinct branch of learning or science forming the subject of one of the Honcurs Schools of the Faculties of Arts and Science, and that he has passed a prescribed examination in such Honours School after attending its third year's course. The Honours Schools recommended in the Report for immediate establish. ment in the University are those of (1) Classics, (2) English, (3) History, (4) Philosophy, (5) Mathematics, (6) Engineering, (7) Chemistry, (8) Zoology, (9) Physiology, and (10) Geology, Mineralogy, and Palæontology. For all of these Honours Schools the Owens College is prepared to supply classes meeting the proposed requirements of the several Schnols. II. The Ordinary degree of B.A. or B.Sc. is to imply that a student has attended, during at least two years, prescribed courses of study (approved of by the University) forming a connected whole, and that he has passed an examination corresponding to the earlier year's course, to be called the Intermediate Examination, and an examination corresponding to the later year's course, to be called the Final Examination. 12. The courses of study, and the corresponding examinations, prescribed for the Ordinary degrees of B.A. and B.Sc., and open to the choice of candidates who have passed either group of the Preliminary Examination, vary according to the predominance in each course (with its examinations) of one branch of learning or science. This predominance is not however such as to warrant the maintenance of the designations given (for convenience' sake) in the Draft Regulations of "mainly Classical, Historical, English, Philosophical, Mathematical, Engineering, Experimental Science, and Biological." Caudidates for an Ordinary B.A. or B.Sc. degree may choose any of these groups, but must go through the whole two years' course, and pass both the examinations of the group chosen. The examinations and classes however largely coincide in particular portions of the several groups. 13. With a view to encourage more advanced study in special branches of learning or science in students whose bent has been determined, or whose capabilities have been developed, at a later stage of their University career, students who have passed the Final Examination for an Urdinary B.A. or B.Sc. degree, are to be allowed to present themselves for examination for a B.A. or B.Sc. degree with Honours, after attending the third, or second and third, year's Honours Course, only in one of the Honours Schools. 14. The degree of Master of Arts or of Science is to be conferred upon Bachelors of Arts of three years' standing, after not le:s than six years from the date of their matriculation. B.A.s who bave graduated with Honours are not to be required to pass any further examination for the M.A. degree; those who have taken he Ordinary B.A. or B.Sc. degree are to be required to pass an examination in some portion of one of the Honours Schools Examinations. 15. The Doctor's degree in the Faculties of Arts or Science is to be conferred upon M.A.s or M.Sc.s who have furnished evidence of special research or learning, to be supplemented when desirable by an examination test.

\section{SCIENTIFIC SERIALS}

Bulletin de l'Academie Imperiale des Sciences de St. Petersbourg, t. xxvii., No. I, February, 1881.-On the results of experiments on the resistance of the air and their application to the solution of problems of firing, by M. Mayevisi. - On variations of the fur and on the geographical distribution of the sea-otter (Enhydris marina), by M. Brandt.-On the integration of partial equations of the first order with several variables whose co-efficients are constant, 